\title{
Cloning and characterization of a mouse liver-specific gene mfrep- 1 , upregulated in liver regeneration
}

\author{
Jun YAN ${ }^{1}$, HaO YING ${ }^{1}$, Fei GU², Jin HE ${ }^{3}$, Yu Li LI ${ }^{3}$, Hui Min LIU ${ }^{3}$, Yong Hua XU ${ }^{1, *}$ \\ ${ }^{1}$ Laboratory of Molecular and Cellular Oncology, Institute of Biochemistry and Cell Biology, Shanghai Institutes \\ for Biological Sciences, Chinese Academy of Sciences, 320 Yueyang Road, Shanghai 200031, China \\ ${ }^{2}$ Department of Surgery, Huashan Hospital, Fudan University, Shanghai 200031, China \\ ${ }^{3}$ Department of Pathology, Changzheng Hospital, Second Military Medical University, Shanghai 200003, China
}

\begin{abstract}
Human fibrinogen-related protein-1/liver fibrinogen-related protein-1 (HFREP-1/LFIRE-1), a liverspecific protein, is a member of fibrinogen superfamily that exerts various biological activities. However, the function of HFREP-1/LFIRE-1 in liver remains unknown. Here we isolated its mouse ortholog gene-mouse fibrinogen-related protein-1 (mfrep-1), which encoded 314 amino acids, exhibiting $80.4 \%$ similarity to HFREP-1/LFIRE-1. Northern blot analysis revealed that 1.2-kb mfrep-1 mRNA was detected selectively in mouse liver. To explore the function of MFREP-1, we examined the levels of mfrep-1 mRNA during regeneration after 70\% partial hepatectomy $(\mathrm{PHx})$ in mice. mfrep-1 mRNA increased in the regenerating liver and reached the first shoulder peak at 2-4 h after PHx. Cycloheximide pretreatment could suppress the induction of mfrep-1, indicating the up-regulation of this gene need de novo protein synthesis. Its mRNA continued to elevate at $6 \mathrm{~h}$ thereafter and reached the second peak at $24 \mathrm{~h}$. The enhanced expression of mfrep-1 maintained high until $72 \mathrm{~h}$ and then declined slowly to the basal level. Immunohistochemistry assessment confirmed the up-regulated expression of MFREP-1 protein in parenchymal cells during liver regeneration. These data suggested that MFREP-1 might play an important role in liver regeneration and be involved in the regulation of cell growth.
\end{abstract}

Key words: $m$ frep-1, in silico cloning, liver regeneration, liver-specific expression.

\section{INTRODUCTION}

Liver regeneration is an ideal model for study of cell proliferation[1],[2]. In intact adult liver the majority of hepatocytes stay in quiescent and highly differentiated status. In the condition of cell loss by surgical resection, infectious, or toxic injury, hepa-

\footnotetext{
* Corresponding author: Prof. Yong Hua XU, Tel/Fax: 008621- 64711349 E-mail: yhxu@sunm.shcnc.ac.cn Abbreviations:HFREP-1/LFIRE-1, human fibrinogen-related protein-1/liver fibrinogen-related protein-1; MFREP-1, mouse fibrinogen-related protein-1; $\mathrm{PHx}$, partial hepatectomy; a.a., amino acid.

Genbank accession number: The cDNA sequence reported here was deposited in GenBank. MFREP-1, AF478470.

Received Jul-4-2002 Revised Oct-25-2002 Accepted Oct-28-2002
}

tocytes almost initiate immediately replication and a wave of cell proliferation appears.

In $70 \%$ partial hepatectomy $(\mathrm{PHx})$ liver regeneration model, the majority of cells in the remnant liver rapidly reenter cell cycle accompanied by the induced expression of a large number of growth-response genes. Several immediate early-phase genes related to cell proliferation can be induced within 2 h. These genes include c-fos, c-jun, etc[3]. The onset of $\mathrm{S}$ phase of cell cycle emerges at about $12 \mathrm{~h}$ and DNA synthesis reached the peak at $24 \mathrm{~h}[4]$. The remainder liver will double its volume after $48 \mathrm{~h}$ and restore the mass of liver before hepatectomy within day 7 to 10 when proliferation ceases[5]. 
Liver-specific genes play important roles in liver functions[3],[6]. lfire-1 gene (GenBank accession number: AF168954) was isolated by our lab and has 97.6\% identity with hfrep-1[7], but a main discrepancy at their 5' untranslated region (manuscript submitted). Since both of them encode the same polypeptide, we designated it as hfrep-1/lfire- 1 here. HFREP-1/LFIRE-1 belongs to fibrinogen superfamily, whose members share a common fibrinogen-like domain at their carboxy-termini[7]. They might act as 'molecular facilitator' participating in the proliferation and adhesion of cells, angiogenesis and carcinogenesis[8-10]. Northern blot assay revealed that $h$ frep-1/lfire-1 was exclusively expressed in normal rat liver and two human hepatoma cell lines, HepG2 and PLC/PRF/5[7]. However, the functions of $h$ frep-1/lfire- 1 remain elusive.

Here we are the first to report the isolation and characterization of mouse ortholog $m$ frep- 1 gene to human hfrep-1/lfre-1, by in silico cloning. The fulllength $m$ frep- 1 cDNA sequence was confirmed by RT-PCR and sequencing. This gene encodes a 314 amino-acid protein exhibiting $80.4 \%$ similarity to the human HFREP-1/LFIRE-1. We investigated the expression of $m$ frep- 1 in mouse multiple tissues by Northern blot analysis. To explore its potential function, we employed liver regeneration model by PHx. After 70\% hepatectomy of mouse liver, $m$ frep1 was induced at $2 \mathrm{~h}$ after $\mathrm{PHx}$ and the second peak arrived after $24 \mathrm{~h}$. The expression of $m$ frep- 1 maintained high until $72 \mathrm{~h}$ and declined to the basal level thereafter. The results suggested that $m$ frep-1, a liver specific gene, may function as a regulator of cell growth in liver regeneration.

\section{MATERIALS AND METHODS}

\section{Animals}

Male C57Bl/6J mice (body weight, 20-25 g) were ether-anesthetized and subjected to midventral laparotomy with 70\% liver hepatectomy as described by Higgins and Anderson[11]. For sham operations, mice were anesthetized, an abdominal incision was made, and the liver was manipulated but not removed. For cycloheximide-treated sample, mice were pretreated $15 \mathrm{~min}$ prior to laparotomy with cycloheximide ( $50 \mathrm{mg} / \mathrm{kg}$ of body weight). All mice were maintained in temperature-controlled rooms under 12 h dark/light cycles to synchronize feeding.

\section{In silico cloning of $m$ frep- 1}

Based on the hfrep-1/lfire-1 sequence, we found its mouse ortholog by EST database searching. We used Blast algorithms through the National Center of Biotechnology Information and downloaded the mouse UniGene cluster Mm. 28340. All of the EST sequences were auto-transformed into the recognizable format for DNASTAR software package (DNASTAR. Inc.) by a selfmade software, called SMART-DNA[12]. These EST sequences were assembled by Seqman program (DNASTAR) and the clone with the longest insertion was purchased. We checked the nucleotide sequence by sequencing the clone in two directions. The primers 5' GGAGGCTCTGTGTGGATGGACTG3' and 5' ATTACAGAAAGGAGATCCCAATGAGG3' were designed according to the sequence above and used in RT-PCR assay with PfuTurbo ${ }^{\circledR}$ DNA polymerase (Stratagene) and mouse liver cDNA as template. The full-length MFREP-1 cDNA was isolated, confirmed by sequencing and submitted to the GenBank.

\section{Computer-aided analysis of mouse MFREP-1}

The deduced amino acid sequence of MFREP-1 was aligned against the GenBank databases (nucleotide, EST and protein) at the National Center for Biotechnology Information, using BLAST to search for sequence matches. The alignment of proteins was done using the MegAlign program (DNASTAR. Inc.). The signal peptide fragment was determined by SignalP program V1.1 (http:/ /www.cbs.dtu.dk/services/signalP)[13].

\section{RNA extraction and Northern blot assay}

Total RNA was isolated by Trizol (GIBCO/BRL). Northern blot assay was performed as described previously[14]. In brief, $30 \mu \mathrm{g}$ of total RNA was separated in $1.0 \%$ agarose formaldehyde gel and transferred to nylon membrane Hybond XL (Pharmacia) and fixed to the membrane by baking at $80^{\circ} \mathrm{C}$ for $2 \mathrm{~h}$. Membranes were probed with full-length $m$ frep- 1 cDNA labeled with $\left[\alpha-{ }^{32} \mathrm{P}\right]$-dCTP (Amersham) by random-primed labeling system (Promega) at 68 ${ }^{\circ} \mathrm{C}$ overnight followed by washing with $0.2 \times \mathrm{SSC} / 0.1 \% \mathrm{SDS}$ at room temperature for $15 \mathrm{~min}$ and then at $60{ }^{\circ} \mathrm{C}$ for $15 \mathrm{~min}$ twice. Then membranes were subjected to phosphor screen with a FLA-3000A plate/Fluorescent Image Analyzer.

\section{Quantitation of mfrep-1 expression level during liver regeneration}

The intensity of $m$ frep- 1 bands during liver regeneration was measured and analyzed by ImageGauge program Ver. 3.12 for band quantification (Fuji Photo Film Co. LTD). The value of $m$ frep- 1 expression was determined by calculating the ratio of the expression level at each time during liver regeneration and that in the intact normal liver tissue, each of which was normalized for the corresponding 18S rRNA expression level. Reproducibility was confirmed by three independent Northern blot assays.

\section{Immunohistochemistry}

Immunohistochemistry was performed as described previously[15]. In brief, paraffin-embedded tissues were sectioned at a 
thickness of 4 to $6 \mathrm{~mm}$ sections and were microwaved for $5 \mathrm{~min}$ for antigen retrieval. After the specific pretreatment procedures, all samples were incubated with $3 \% \mathrm{H}_{2} \mathrm{O}_{2}$ in methanol solution for 12 min at room temperature to block endogenous peroxidases. Then the samples were incubated with human HFREP-1/LFIRE-1 polyclonal antibody (prepared in our lab) to localize the MFREP1 proteins in the cells, and visualized by AEC (Maxin Biotech. Inc.). Sections were blocked and counterstained with hematoxylin. Sections incubated in rabbit serum instead of the corresponding primary antibody were used for comparison as negative control.

\section{RESULTS}

\section{Cloning and characterization of the Full-length} mfrep-1 cDNA

In order to obtain the mouse ortholog of human HFREP-1/LFIRE-1, we screened the GenBank EST database using HFREP-1/LFIRE-1 cDNA sequence as template. We found that two ESTs (5' EST: AI181881 and 3' EST: AI173236), both of which belong to a clone IMAGE: 1450566 from Washington University school of Medicine, contained the longest insert among 57 EST entries in mouse UniGene cluster Mm. 28340. We purchased this clone and sequenced the insert.

To examine the authenticity of the sequence of insert, we designed the primers according to the sequence of 5' EST (AI181881) and 3' EST (AI173236) and amplified the ORF of this gene by RT-PCR with mouse adult liver cDNA as template. Sequencing of the resultant PCR product confirmed the identity of the cDNA from IMAGE: 1450566, indicating that we had isolated a novel cDNA of 1127 -bp transcript. This cDNA sequence has a complete Kozak sequence with AGAATGG around the second ATG triplet (Fig 1A)[16]. As illustrated in Fig $1 \mathrm{~A}$, the ORF extends from the ATG (at position 98) codon to the TAA (at position 1042), and encodes 314 amino acids with a predicted molecular mass of $36 \mathrm{kDa}$. According to the results from Northern blot analysis, we inferred that we had obtained the fulllength $1.2 \mathrm{~kb}$ cDNA. We designated it as $m$ frep- 1 (mouse fibrinogen-related protein-1).

\section{Sequence comparison}

The deduced protein from $m$ frep- 1 cDNA has a 230-a.a. fibrinogen-related domain at its carboxyterminus, which contains four conserved cysteine residues (Fig 1A, 2B). The $\mathrm{N}$-terminal sequence con- sisting of 22 a.a. was assigned as the signal sequence based on its hydrophobic nature (Fig 1B)[13]. After

\section{A}

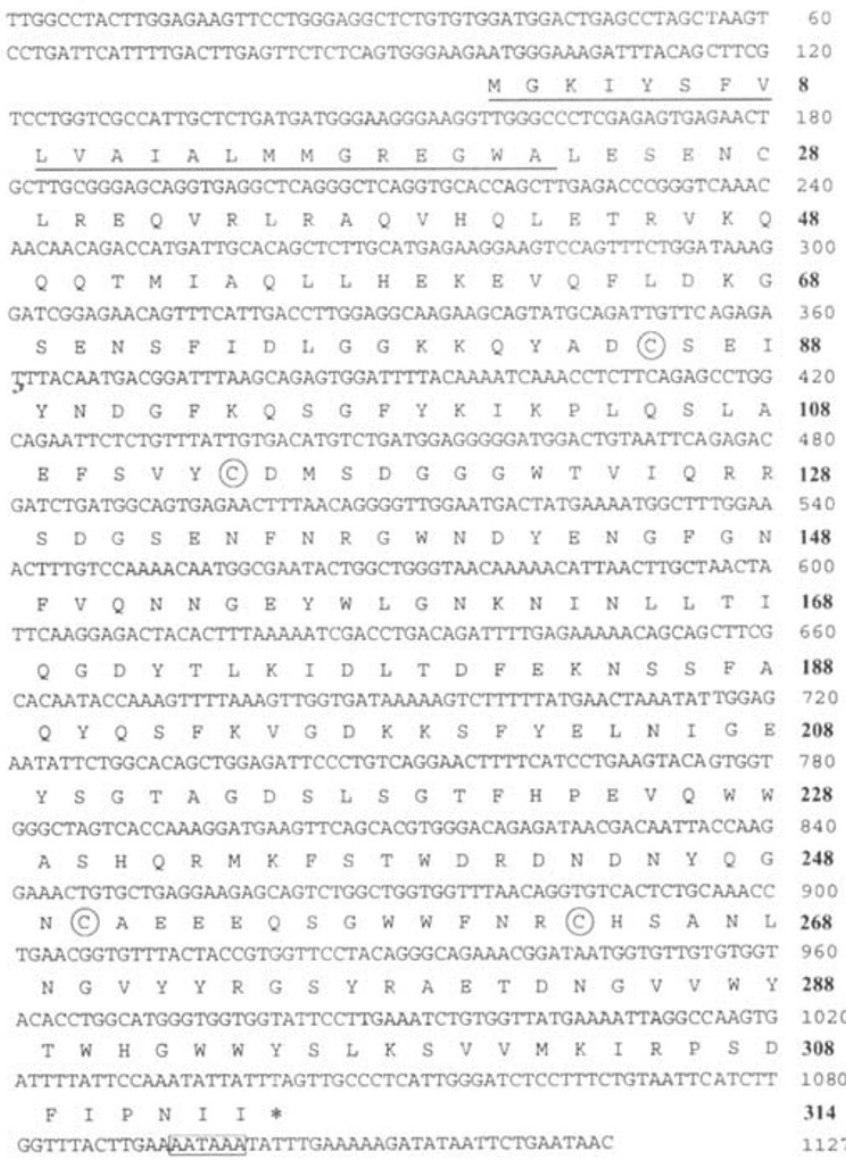

B

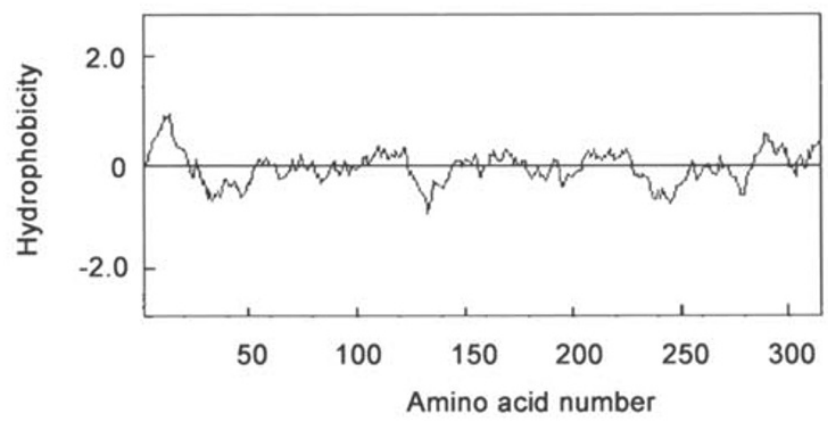

Fig 1. A. The nucleotide and amino acid sequence of mouse MFREP-1. One putative signal peptide predicated is underlined. Four conserved cysteine residues are enclosed in circle. The asterisk indicates a termination codon. One possible polyadenylation signal is boxed. B. Predicted hydrophobic plot of mouse MFREP-1 by Protean program (DNAStar package). Negative values indicate hydrophilic regions and positive values indicate hydrophobic region. 
comparing MFREP-1 with HFREP-1/LFIRE-1, we found the predicted a.a. sequence of MFREP-1 has $80.4 \%$ similarity with its human ortholog HFREP1/LFIRE-1. The MFREP-1 protein resembled human HFREP-1/LFIRE-1 closely except 2 more unconserved a.a. at $\mathrm{N}$-terminal end and 59 a.a. resi- due variations between these two proteins, most of which are with the same hydrophathy (Fig 2A).

We compared the deduced a.a. sequence of MFREP-1 with those of other members of the fibrinogen superfamily (Fig 2B). The similarity and divergence is shown in the table (Fig 3A), using Pro-

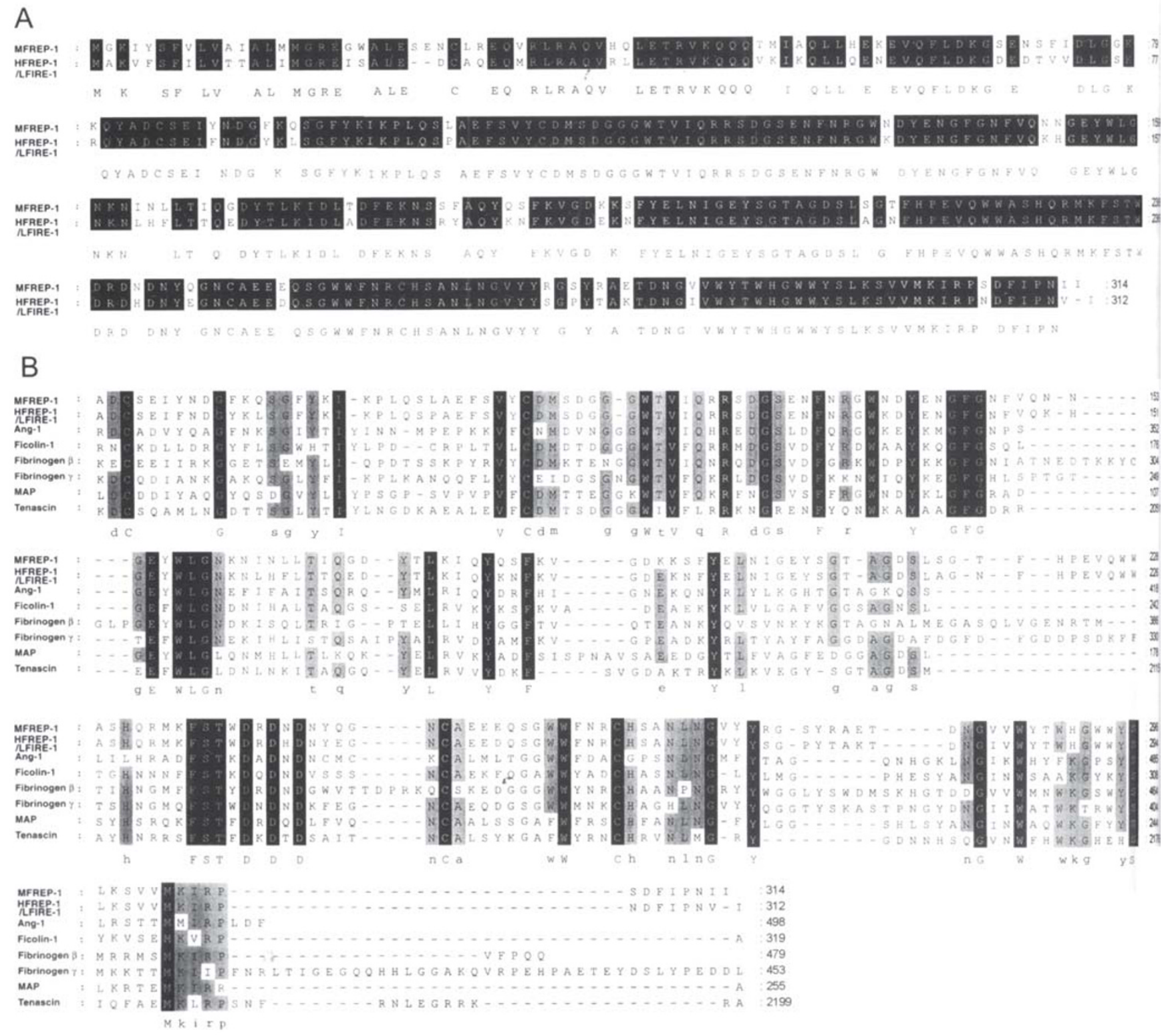

Fig 2. Comparison of MFREP-1 with other members of fibrinogen superfamily. A. Comparison of deduced amino acid sequences of mouse MFREP-1 and human HFREP-1/LFIRE-1. Shaded areas indicate identical amino acids. B. Amino acid sequences alignment of fibrinogen-related domain of MFREP-1 with those of seven other human members of fibrinogen superfamily: HFREP-1/LFIRE-1; angiopoietin-1; ficolin-1; fibrinogen beta; fibrinogen gamma; human MAP, and tenascin. Dark shaded areas indicate the residues conserved in all eight sequences, gray shaded areas indicate residues conserved at least in six sequences. 
A
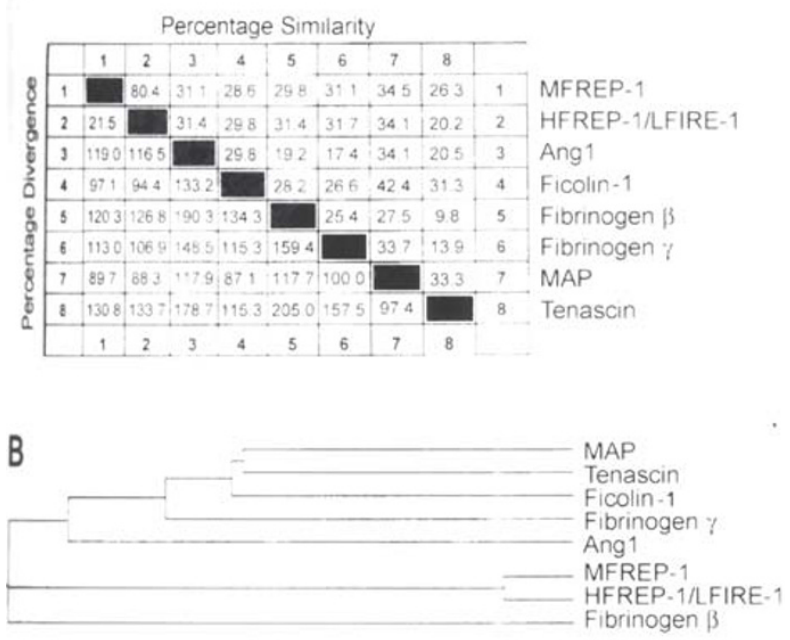

Fig 3. A. Similarity and divergence of MFREP-1 among members of fibrinogen superfamily. B. Phylogenetic tree established with the data from Megalign.

tean program (DNASTAR, Inc.). From these alignments using Megalign, the phylogenetic tree was established (Fig 3B). Our data indicate that MFREP1 belongs to fibrinogen superfamily.

Tissue-specific expression of $m$ frep- 1

Analysis of the tissue distribution of $m$ frep- 1 transcript was carried out using total RNA isolated from mouse uterus, ovary, bladder, pancreas, placenta, oesophagus, brain, heart, lung, stomach, liver, intestine, spleen, kidney, testis, muscle. Our data showed that the $m$ frep- 1 transcript appears as a band of $1.2 \mathrm{~kb}$ mRNA only in mouse liver (Fig 4). There existed no detectable signals in other tissues we tested.

Up-regulated expression of mfrep-1 mRNA and protein during liver regeneration

To explore the function of $m$ frep- 1 in vivo, we analyzed the kinetics of $m$ frep- 1 gene expression during liver regeneration after $70 \% \mathrm{PHx}$. In the $\mathrm{PHx}$ mice, the liver weight was restored to $96 \%$ of the original weight at $168 \mathrm{~h}$ after $\mathrm{PHx}$, which indicated a standard time frame of $\mathrm{PHx}$ regeneration. As shown in Fig 4, the expression of $m$ frep- 1 was obviously elevated in $12 \mathrm{~h}$ regenerative liver compared with normal tissues and $12 \mathrm{~h}$ sham operation tissue. Then, the kinetic change of $m$ frep- 1 expression levels during liver regeneration was examined by Northern blot assay. The level of $m$ frep- 1 mRNA remained almost unchanged at $0.5 \mathrm{~h}$ and increased to 2.13 fold above quiescent level at $2 \mathrm{~h}$ in the $\mathrm{PHx}$ mice and maintained thereafter (Fig 5A and B). Interestingly, $m$ frep- 1 expression continued to elevate at $6 \mathrm{~h}$. The expression level reached at 3.42folds higher than control level $24 \mathrm{~h}$ after PHx (Fig $5 \mathrm{~A}$ and B). Then, the expression level of $m$ frep- 1 RNA slowly declined from day 3 to $d 7$ around 3fold above quiescent level, and reduced to 2 -fold at

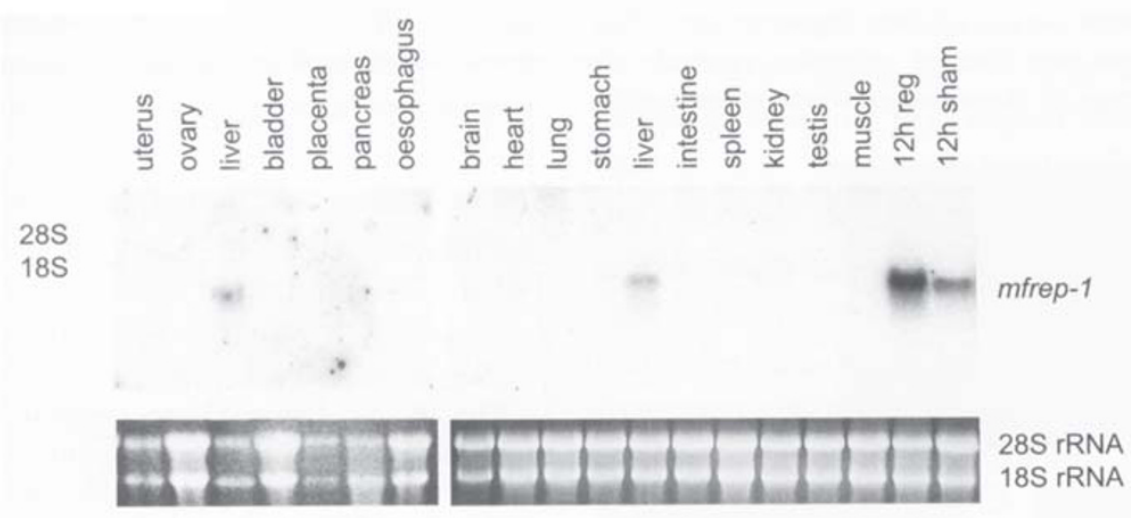

Fig 4. Northern blot analysis of mfrep-1 mRNA expression in multiple mouse tissue. Total RNA was extracted from 16 various mouse tissues and liver tissues $12 \mathrm{~h}$ after partial hepatectomy (12 h reg) and $12 \mathrm{~h}$ after sham operation (12 h sham). $30 \mu \mathrm{g}$ of total RNA was electrophoresed on a $1.0 \%$ agarose/formaldehyde gel, transferred to a nylon membrane and hybridized with [ $\alpha$ $\left.{ }^{32} \mathrm{P}\right]$ dCTP-labeled $m$ frep- 1 cDNA probe. rRNA is shown as loading control. The multiple tissue sources of the mRNA in each lane are indicated at top of the blot. 

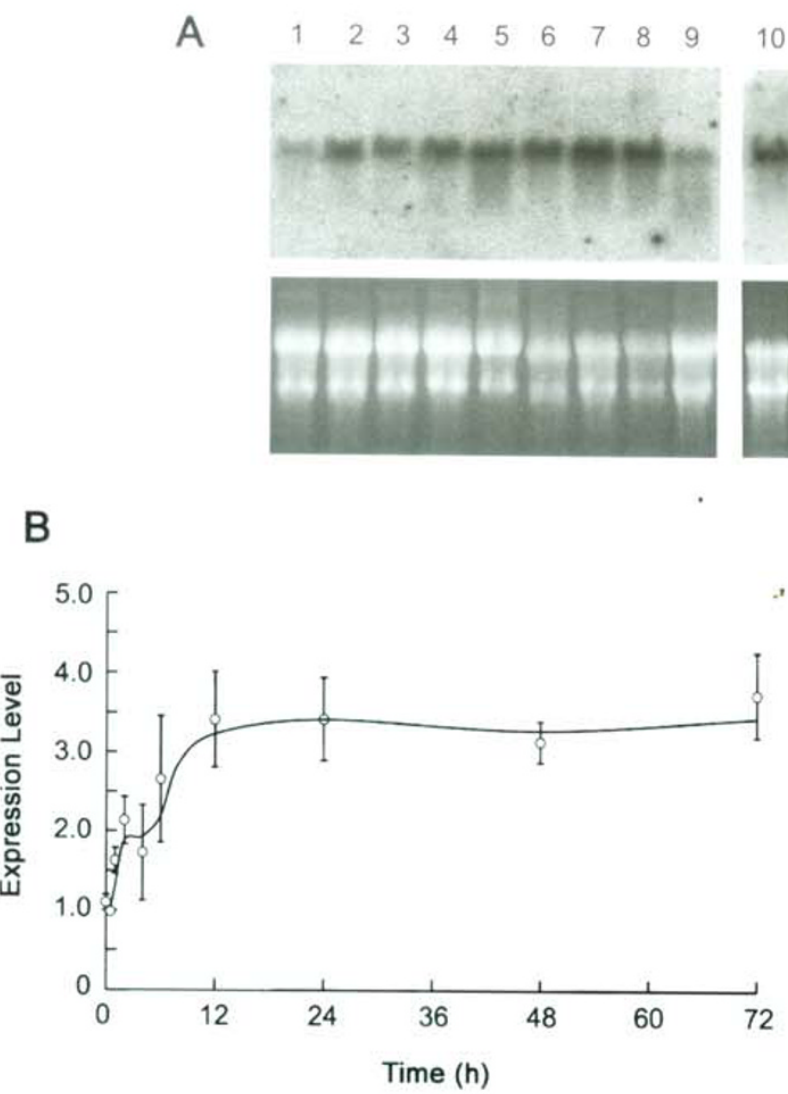

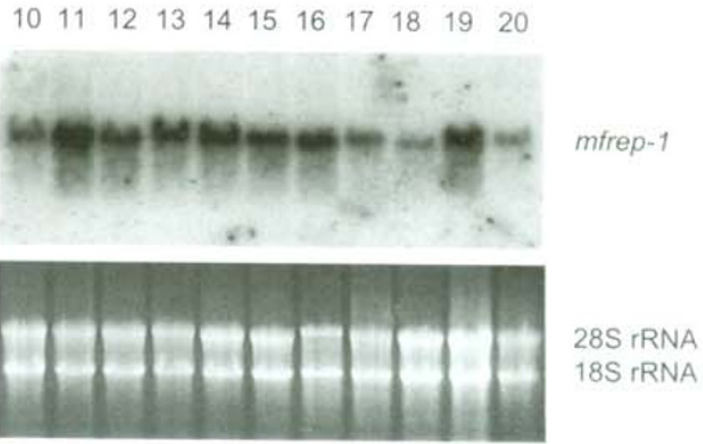

C

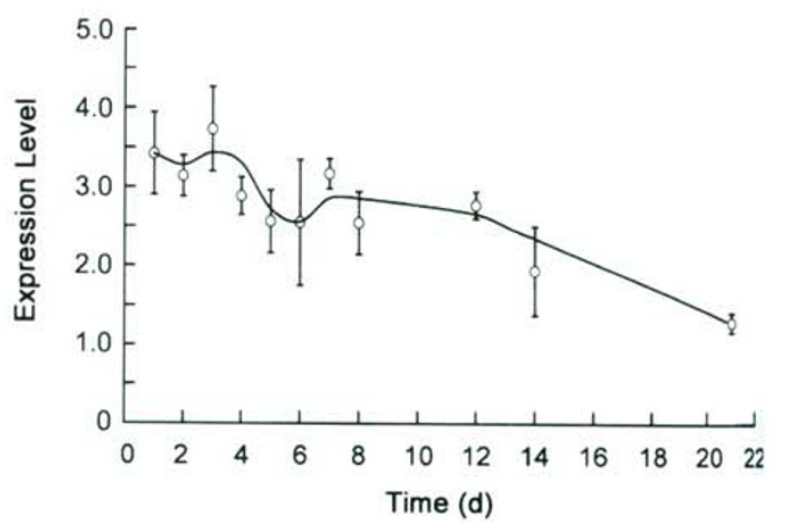

Fig 5. Expression kinetics of mfrep-1 during liver regeneration after PHx. A. The expression of mfrep-1 mRNAs during liver regeneration were determined by Northern blot assay. Total mRNAs was obtained from liver tissues $0.5 \mathrm{~h}$ (Lane 2), $1 \mathrm{~h}$ (Lane 3), $2 \mathrm{~h}$ (Lane 4 and 19), $4 \mathrm{~h}$ (Lane 5), $6 \mathrm{~h}$ (Lane 6), $12 \mathrm{~h}$ (Lane 7), $1 \mathrm{~d}$ (Lane 8), 2 days (Lane 9), 3 days (Lane 10), 4 days (Lane 11), $5 \mathrm{~d}$ (Lane 12), $6 \mathrm{~d}$ (Lane 13), $7 \mathrm{~d}$ (Lane 14), $8 \mathrm{~d}$ (Lane 15), $12 \mathrm{~d}$ (Lane 16), $14 \mathrm{~d}$ (Lane 17), $21 \mathrm{~d}$ (Lane 18) after PHx, before PHx (Lane 9) as well as RNA from $2 \mathrm{~h}$ after $70 \%$ hepatectomy with cycloheximide (50 mg/kg of body weight) pretreatment (lane 20). $30 \mu \mathrm{g}$ of mRNAs was separated in $1.0 \%$ agarose gel containing formaldehyde. EB staining of $18 \mathrm{~S}$ and $28 \mathrm{~S}$ rRNA was used as loading control. B. Graphic representation of mfrep-1 mRNA level in the growth period of liver regeneration. C. Graphic representation of $m$ frep-1 mRNA level in the long-term period of liver regeneration. The quantity of mfrep-1 determined by densitometries analysis as shown as increase over that of untreated controls after normalization against signals of $18 \mathrm{~s}$ control. Each point represents the average of three independent experiments.
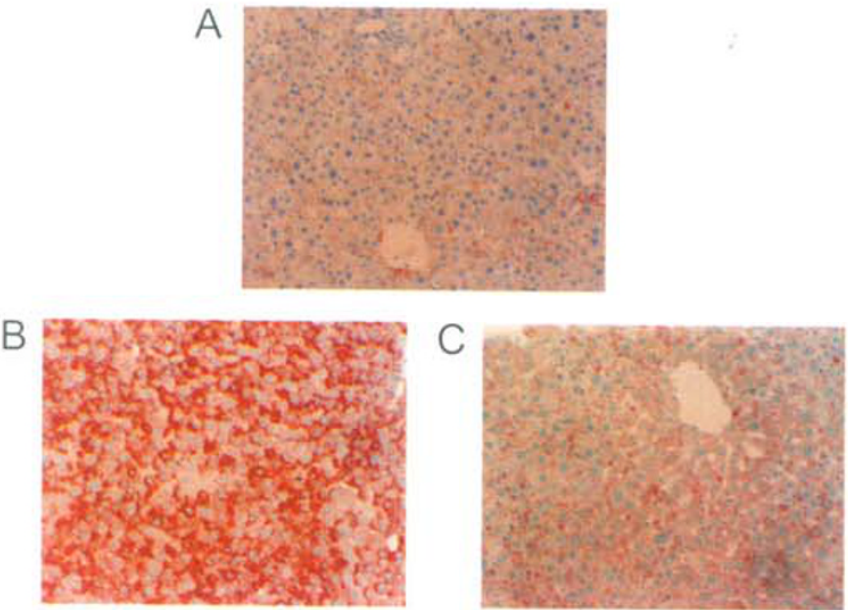

Fig 6. Immunohistochemical assessment of MFREP-1 protein expression during mouse liver regeneration after PHx. Paraffin-embedded sections (4 to $6 \mu \mathrm{m}$ ) were pretreated and immunodetected by anti-HFREP-1/LFIRE1 polyclonal antibody. The samples were visualized by AEC (Maxin Biotech. Inc.). Sections were counterstained with hematoxylin. A. mouse intact adult liver, B. mouse liver $12 \mathrm{~h}$ after $\mathrm{PHx}, \quad$ C. mouse liver $12 \mathrm{~h}$ after sham operation. Magnitude, $\times 200$. 
d 14 (Fig 5A and C). At d 21, its expression level reached the control level. Pretreatment with protein synthesis inhibitor cycloheximide down-regulated $m$ frep- 1 expression level at $2 \mathrm{~h}$ after $\mathrm{PHx}$, indicating the up-regulated expression of $m$ frep- 1 needs prior protein synthesis of induction (Fig 5A).

To check whether the up-regulated mRNA expression of mfrep-1 was accompanied by the enhanced expression of MFREP-1 protein in mouse liver regeneration, we performed immunohistochemistry assessment using the polyclonal antibody against human HFREP-1/LFIRE-1. Since this polyclonal antibody is prepared by using HFREP-1/LFIRE-1 fragment (a.a. 22-312) as antigen, it can also recognize the evolutionarily conserved MFREP-1. Immunohistochemsitry results revealed that the signals were seen from liver parenchyma cells. The signals were not very strong in normal intact mouse liver and sham-operation mouse liver, but intensive in mouse remnant liver $12 \mathrm{~h}$ after $\mathrm{PHx}$, which coincided with the enhanced expression of mfrep-1 mRNA (Fig 6).

\section{DISCUSSION}

The isolation and characterization of mouse ortholog gene can offer important information on the structural conservation and potential function of a specific gene. The concept of comparative gene identification (CGI) has been previously used by many laboratories to search for orthologous genes once a particular gene of interest has been identified in other species. Nowadays, with the development of EST database, molecular cloning in silico comes to be an efficient method to isolate the fulllength cDNA sequence[17],[18].

We described here for the first time a novel mouse liver-specific gene for a protein designated mfrep-1, an ortholog gene of human hfrep-1/lfire-1 that has been identified as a liver cancer associated gene. Both of mfrep- 1 and hfrep-1/lfire- 1 belong to fibrinogen superfamily, with a $220 \sim 250$-a.a. fibrinogen-like domain at carboxy-terminus. Fibrinogen $\beta$ and $\gamma$ is composed of two each of three homologous polypeptide chains ( $\alpha 2, \beta 2, \gamma 2$ ) and is an essential protein for blood clotting. Tenascins take responsibility for cell adhesion, whereas angiopoietins can stimulate angiogenesis[9]. The precise functions of the fibrinogen-like domain-containing proteins have not been fully elucidated. $m$ frep-1, like $h$ frep-1/lfire-1, is a liver-specific gene that may play an essential role in liver functions. To investigate the potential role of MFREP-1 in cell proliferation regulation, we used mouse liver regeneration model to analyze the expression kinetics of $m$ frep-1. The processes of liver regeneration reflect very important events in the cell cycle such as initiation of cell division, termination of cell growth and cell differentiation[19],[20].

The expression of early genes in $\mathrm{PHx}$ can be categorized into two kinds, immediate-early genes and delayed-early genes. Immediate-early genes are induced in a protein synthesis-independent manner in the transition from the normal quiescent state of the liver (G0) to the growth phase (G1). The expression of c-fos and c-jun proto-oncogenes, two wellknown immediate-early genes, was induced within $1 \mathrm{~h}$ after $\mathrm{PHx}$ and can be superinduced by pretreatment with cycloheximide. The protein products of these nuclear proto-oncogenes are expressed abundantly in most proliferating cells[4]. At the cellular level, proteins encoded by immediate-early genes may help control progression through G1 phase. The induced expression of delayed-early genes occurs several hours later and requires new protein synthesis. Delayed-early genes are also important modulators of the regenerative response. The temporal profiles of Bcl-x mRNA expression, which is regarded as delayed-early gene, displays two distinct peaks at 4 hours and 48 to $72 \mathrm{~h}$, suggesting a cellcycle-dependent regulation[21].

In PHx model, the level of mfrep- 1 mRNA was found to reach its first higher level at $2 \mathrm{~h}$ (2.13 times higher than the basal level) after 70\% PHx. Our data showed that after treatment of cycloheximide, a protein synthesis inhibitor, $m$ frep -1 was reduced rather superinduced $2 \mathrm{~h}$ after PHx. $m$ frep- 1 can thus be characterized as a delayed early gene during liver regeneration in light of its expression during G1 phase and its requirement of protein synthesis for induction.

It has been demonstrated that the peak rate of DNA synthesis occurs at about $24 \mathrm{~h}$ after $\mathrm{PHx}$ and then a minor peak of DNA synthesis appears at about day 3[5]. After the shoulder peak during 2-4 $\mathrm{h}$, the expression level of $m$ frep- 1 mRNA reached nearly 3.42 -fold at $24 \mathrm{~h}$ and was slightly increased to 3.73 -fold at day 3 . These two peaks of expression 
corresponded to the first and second peak of DNA synthesis in hepatocytes. Thus, the results suggest that the $m$ frep- 1 gene is closely associated with DNA synthesis in liver regeneration, and imply that it might be involved in the enhancement of cell replication.

Furthermore, the expression pattern of $m$ frep- 1 gene resembles those of liver-specific genes, such as c/ebp $\alpha$ which shows maximal expression after the growth period of liver regeneration[3],[4]. The expression level of c/ebp $\alpha$ reaches a broad peak between 60 and $216 \mathrm{~h}$ after $\mathrm{PHx}$, correlating with the time when the liver cease growing[22]. This is consistent with the fact that c/ebp $\alpha$ is related with the differentiated state, and in some cells c/ebp $\alpha$ can arrest the proliferative phase[23],[24]. Moreover, the expression of some growth-inhibitory genes, or example, $\operatorname{tgf}-\beta$ and activin a, are also up-regulated and kept high during this period in liver regeneration[25-29]. Here we demonstrated that $m$ frep- 1 maintained at more than 2.5-fold the control level after the wave of DNA synthesis. Therefore, we conclude that this gene plays an important role in growth regulation of liver regeneration, but, the mechanism and the significance of enhanced expression of $m$ frep- 1 after day 7 still remains to be defined.

In conclusion, our results revealed that liver-specific gene $m$ frep- 1 was enhanced in liver regeneration after PHx. Its expression pattern in liver regeneration suggested that it might play an essential role in cell proliferation.

\section{ACKNOWLEDGMENTS}

This work was supported by research grants from the Special Funds for Major State Basic Research of China (Grant G1999053905).

\section{REFERENCES}

[1] Michalopoulos GK. Liver regeneration: molecular mechanisms of growth control. FASEB J 1990; 4:176-87.

[2] Fausto N. Liver Regeneration. In: The Liver: Arias IM, Boyes JL, Jakoby WB, Fausto N, Schachter DA, Shafritz DA, Eds Biology and Pathobiology. Raven Press, New York 1994:1059-84.

[3] Taub R. Transcriptional control of liver regeneration. FASEB J 1996; 10:413-27.

[4] Steer CJ. Liver regeneration. FASEB J 1995; 9:1396400.

[5] Michalopoulos GK, DeFrances MC. Liver regeneration. Science 1997; 276:60-6.

[6] Zaret KS. Genetic control of hepatocyte differentiation.
In: Arias IM, Boyer JL, Fausto N, Jakoby WB, Schachter DA, Shafritz DA, Eds. The Liver: Biology and Pathobiology. Raven Press: New York 1994:53-68.

[7] Yamamoto T, Gotoh M, Sasaki H, Terada M, Kitajima M, Hirohashi S. Molecular cloning and initial characterization of a novel fibrinogen-related gene. Biochem Biophys Res Commun 1993; 193:681-7.

[8] Jones PL, Jones FS. Tenascin-C in development and disease: gene regulation and cell function. Matrix Biol 2000; 19:581-96.

[9] Davis S, et al. Isolation of angiopoietin-1, a ligand for the TIE2 receptor, by secretion-trap expression cloning. Cell 87:1161-9.

[10] Matsushita M, Fujita T. Ficolins and the lectin complement pathway. Immunol Rev 2001; 180:78-85.

[11] Higgins GM, Anderson RM. Experimental pathology of the liver. Arch Pathol 1931; 12:186-202.

[12] Ying H, Yu YL, Xu YH. Cloning and Characterization of F-LANa, Upregulated in Human Liver Cancer. Biochem Biophys Res Commun 2001; 286:394-400.

[13] Nielsen H, Engelbrecht J, Brunak S, von Heijne G. Identification of prokaryotic and eukaryotic signal peptides and prediction of their cleavage sites. Protein Engineering 1997; 10:1-6.

[14] Fang CM, Xu YH. Down-regulated expression of atypical PKC-binding domain deleted asip isoforms in human hepatocellular carcinomas. Cell Res 2001; 11:223-9.

[15] Wang FD, Bian W, Kong LW, Zhao FJ, Guo JS, Jing NH. Maternal zinc deficiency impairs brain nestin expression in prenatal and postnatal mice. Cell Res 2001; 11: 135-41.

[16] Kozak M. The scanning model for translation: An update. J Cell Biol 1989; 108:229-41.

[17] Aaronson JS, et al. Toward the development of a gene index to the human genome: an assessment of the nature of high-throughput EST sequence data. Genome Res 1996; 6:829-45.

[18] Miller G, Fuchs R, Lai E. IMAGE cDNA clones, UniGene clustering, and ACeDB: an integrated resource for expressed sequence information. Genome Res 1997; 7: 1027-32.

[19] Pistoi S, Morello D. Prometheus? myth revisited: transgenic mice as a powerful tool to study liver regeneration. FASEB J 1996; 10:819-28.

[20] Thorgeirsson SS. Hepatic stem cells in liver regeneration. FASEB J 1996; 10:1249-56.

[21] Tzung SP, Fausto N, Hockenbery DM. Expression of Bcl2 family during liver regeneratin and identification of Bcl-x as a delayed-early response gene. Am J Pathol 1997; 150:1985-95

[22] Haber BA, Mohn KL, Diamond RH. Taub R. Induction patterns of 70 genes during nine days after hepatectomy define the temporal course of liver regeneration. J Clin Invest 1993; 91:1319-26.

[23] Greenbaum LE, Cressman DE, Haber BA, Taub R. Coexistence of $\mathrm{C} / \mathrm{EBP}$, growth-induced proteins and DNA synthesis in hepatocytes during liver regeneration. J Clin Invest 1995; 96:1351-65.

[24] McKnight SL. McBindall-a better name for CCAAT/en- 
hancer binding proteins? Cell 2001; 107:259-61.

[25] Thompson NL, Mead JE, Braun L, Goyette M, Shank PR, Fausto N. Sequential protooncogene expression during rat liver regeneration. Cancer Res 1986; 46:3111-7.

[26] Ujike K. et al. Kinetics of expression of connective tissue growth factor gene during liver regeneration after partial hepatectomy and D-Galactosamine-induced liver injury in rats. Biochem Biophys Res Commun 2000; 277: 448-54.

[27] Russell WE, Coffey Jr RJ, Ouellette AJ, Moses HL. Type transforming growth factor reversibly inhibits the early proliferative response to partial hepatectomy in the rat. Proc Natl Acad Sci USA 1988; 85:5126-30.

[28] Date M, Matuzaki K, Matsushita M, Tahashi Y, Sakitani K, Inoue K. Differential regulation of activin A for hepatocyte growth and fibronectin synthesis in rat liver injure. J Hepatol 2000; 32:251-60.

[29] Braun L, Mead, JE, Panzica M, Mikumo R, Bell GI, Fausto N. Transforming growth factor $b$ mRNA increase during liver generation: A possible paracrine mechanism growth regulation. Proc Natl Acad Sci USA 1988;85;1539-1543 